\title{
Review: mucolytic drugs reduce exacerbations, illness days, and antibiotic use in chronic bronchitis and chronic obstructive pulmonary disease
}

Poole PJ, Black PN. Oral mucolytic drugs for exacerbations of chronic obstructive pulmonary disease: systematic review. BMJ 2001 May 26;322:1271-4.

Poole PJ, Black PN. Mucolytic agents for chronic bronchitis. Cochrane Database Syst Rev 2001;(2):CD001287 (latest version 17Jan 2000).

QUESTION: In patients with chronic bronchitis or chronic obstructive pulmonary disease (COPD), do mucolytic drugs reduce exacerbations or days of illness?

\section{Data sources}

Studies were identified by searching the Cochrane Airways Group register of studies (compiled by searching Medline, EMBASE/Excerpta Medica, and CINAHL, and hand searching respiratory journals and meeting abstracts). Reference lists of articles were scanned, and researchers in the field and pharmaceutical companies were contacted.

\section{Study selection}

Studies were selected if they were randomised, double blind, placebo controlled trials of oral mucolytic drugs taken regularly for $\geqslant 2$ months by adults who were $>20$ years of age and had chronic bronchitis or COPD. Studies on inhaled mucolytic drugs, combinations of mucolytic drugs with antibiotics or bronchodilators, deoxyribonucleases, and such proteases as trypsin were excluded, as were studies on patients with asthma or cystic fibrosis.

\section{Data extraction}

Data were extracted on study country and duration, clinical criteria, patient age, smoking, intervention, and quality of study methods. Summary statistics were used. Main outcomes were number of acute exacerbations, days of illness, and days taking antibiotics.

\section{Main results}

23 of 27 studies that met selection criteria reported data on the main outcomes. Patients had chronic bronchitis in 21 studies and COPD in 2 studies. Follow up ranged from 2 to 24 months (mean 6 mo). Studies were done in Italy (11 studies), the UK (4 studies), Sweden (2 studies), Europe (2 studies), Germany (2 studies), Denmark (1 study), and the USA (1 study). Mucolytic drugs were better than placebo for reducing exacerbations $(p<0.001)$, days of illness $(p<0.001)$, and days of antibiotic use $(\mathrm{p}<0.001)$ (table).

\section{Conclusion}

In patients with chronic bronchitis or chronic obstructive pulmonary disease, mucolytic drugs reduce exacerbations, days of illness, and days of antibiotic use.
Mucolytic drugs v placebo for chromic bronchitis or chronic obstructive pulmonary disease*

\begin{tabular}{|c|c|c|c|c|}
\hline \multirow{2}{*}{$\begin{array}{l}\text { Outcomes at } \\
\text { mean } 6 \text { months }\end{array}$} & \multicolumn{2}{|c|}{ Weighted mean } & \multirow{2}{*}{$\begin{array}{l}\text { Weighted mean } \\
\text { difference } \\
(95 \% \mathrm{Cl}) \dagger\end{array}$} & \\
\hline & Mucolytics & Placebo & & \\
\hline $\begin{array}{l}\text { Number of exacerbations } \\
\text { per patient per month }\end{array}$ & 0.09 & 0.16 & 0.07 (0.05 to 0.08$)$ & \\
\hline Days of illness & 0.75 & 1.31 & 0.56 (0.35 to 0.77$)$ & \\
\hline \multirow[t]{3}{*}{ Days of antibiotic use } & 0.67 & 1.20 & $0.53(0.31$ to 0.76$)$ & \\
\hline & \multicolumn{2}{|c|}{ Weighted event rates } & & \\
\hline & Mucolytics & Placebo & RBI (CI) & NNT (CI) \\
\hline $\begin{array}{r}\text { Patients with no } \\
\text { exacerbations }\end{array}$ & $60 \%$ & $42 \%$ & $43 \%$ (34 to 52 ) & 6 (5 to 7 ) \\
\hline
\end{tabular}

*Abbreviations defined in glossary; weighted mean, $\mathrm{RBI}, \mathrm{NNT}$, and $\mathrm{Cl}$ calculated from data in article. †All differences favour the mucolytic group.

\section{COMMENTARY}

Tracheobronchial mucus hypersecretion contributes to the symptoms of COPD and is associated with an increased risk of hospital admission and an accelerated decline in $\mathrm{FEV}_{1}{ }^{1}$ Nevertheless, evidence that oral mucolytic agents have an important clinical effect has been limited, and routine use of such agents is not recommended in the latest COPD guidelines published by the European Respiratory Society, ${ }^{2}$ British Thoracic Society, ${ }^{3}$ American Thoracic Society, and Global Initiative for COPD (National, Heart, Lung, and Blood Institute and World Health Organization)..$^{5}$

The systematic review by Poole and Black provides a helpful analysis of relevant trials: 23 randomised controlled trials of 10 different agents. Overall, mucolytic agents provided a modest reduction in both the number and duration of symptomatic exacerbations, but lung function was not improved and hospital admission rates were not reported. The most widely studied medication was acetylcysteine (12 studies), and the antioxidant properties of this agent, especially when it is used orally, may be more important than the mucolytic activity. ${ }^{6}$ Of all the agents tested, only acetylcysteine is available in the USA (but is not approved for oral use as a mucus-modifying agent in the USA).

On the basis of the perspective provided by Poole and Black, and until such time that further information is available, it is reasonable to consider the use of mucolytic agents (if locally available) in a subset of COPD patients with particularly viscous sputum or frequent and severe exacerbations.

Herbert P Wiedemann, MD Cleveland Clinic Foundation, Cleveland, Ohio, USA,

1 Aboussouan LS. UpToDate Medicine 2001 [CD-ROM]. http://www.uptodate.com.

2 Siafakas NM, Vermeire P, Pride NB, et al. Eur Respir J 1995;8:1398-420.

3 The COPD Guidelines Group of the Standards of Care Committee of the BTS. Thorax 1997;52(Suppl 5):S1-28.

4 American Thoracic Society. Am J Respir Crit Care Med 1995;152:S77-S121.

5 Pauwels RA, Buist AS, Calverley PM, et al. Am J Respir Crit Care Med 2001;163:1256-76.

6 Ekberg-Jansson A, Larsson S, Lofdahl CG. BMJ 2001;322:1259-61. 